\title{
Competências do professor no processo de ensino-aprendizagem de língua estrangeira
}

\author{
Douglas Altamiro Consolo \\ UNESP - São José do Rio Preto \\ dconsolo@terra.com.br \\ Cristina Francisca de Carvalho Porto \\ UNESP - São José do Rio Preto \\ crisfcporto@ig.com.br
}

\section{Resumo}

Neste artigo objetiva-se refletir sobre as competências necessárias ao professor de língua estrangeira para que este atue eficazmente no processo de ensino-aprendizagem. Para fundamentar esta discussão tomam-se como base teórica as obras de Paulo Freire (2001), Philippe Perrenoud (2000), Edgar Morin (2003), Maurice Tardif (2002) e Almeida Filho (1999), além de outros estudos acerca do tema, realizando assim uma discussão entre diferentes textos que abordam esta mesma problemática. O principal objetivo é compreender um pouco mais sobre os saberes docentes necessários a uma boa atuação do professor de línguas estrangeiras na atualidade. Esperamos, com tais reflexões, salientar a importância das competências docentes para o processo de ensino-aprendizagem de língua estrangeira e, consequentemente, para uma prática docente mais qualificada.

Palavras-chave: competências; formação de professores; língua estrangeira; prática docente.

\begin{abstract}
In this article we discuss competences demanded from the foreign language teacher for him or her to perform in the teaching-learning process efficiently. Our reflections are based mainly on Paulo Freire (2001), Philippe Perrenoud (2000), Edgar Morin (2003), Maurice Tardif (2002) and Almeida Filho (1999), providing, in this way, a reflective dialogue among studies that focus on teachers' competences. The main objective is a better understanding of the necessary knowledge about teaching practices so that foreign language
\end{abstract}


teachers' actions can meet the needs of education at present. We expect to highlight important issues in the development of the aforementioned competences, and suggest that their development can contribute for better language teaching.

Keywords: competences; teacher development; foreign language; teaching practice.

\section{Introdução}

Atualmente muito tem se exigido daqueles que resolvem seguir o ofício de professor. Possuir apenas um conhecimento amplo e sólido do conteúdo estudado na graduação não é suficiente. O professor deve ter outras competências - as quais especificaremos no decorrer deste texto -, envolvendo todo o ambiente escolar e aqueles que dele fazem parte, isto é, direção, funcionários, colegas de profissão, alunos e pais de alunos. No intuito de refletir sobre tais competências, iniciamos então esta discussão.

Quando falamos em professores de línguas, uma das primeiras competências que nos vêm à mente é a competência linguística, mas esta é apenas uma das competências necessárias à boa atuação desse profissional. Outras competências, conforme abordamos neste artigo, precisam ser explicitadas nas reflexões sobre a formação docente e integrar o perfil dos professores.

$O$ foco principal deste trabalho parte do seguinte questionamento: quais competências são necessárias na atualidade para que um professor seja considerado um bom profissional?Como base para nossas reflexões, abordaremos os seguintes autores: Paulo Freire (2001), Philippe Perrenoud (2000), Edgar Morin (2003), Maurice Tardif (2002) e Almeida Filho (1999), além de estudos de outros pesquisadores que discorrem acerca do tema.

Apresentamos na primeira parte deste artigo, denominada "Competências necessárias para o processo de ensino-aprendizagem", competências que são inerentes e fundamentais a qualquer professor, não importando a sua área de atuação, se línguas, história, geografia, matemática, etc.; já na segunda parte do texto em "Competências necessárias ao professor de língua estrangeira" (doravante LE), nossa reflexão direciona-se especificamente à área de línguas estrangeiras. 
O sentido de competência aqui empregado é aquele estabelecido por Perrenoud (2000), ou seja, a competência é a capacidade do indivíduo de agir eficazmente em um determinado tipo de situação, apoiando-se em conhecimentos, sem, contudo, limitar-se a eles; é a faculdade de mobilizar recursos cognitivos, saberes, habilidades e informações, para solucionar, com eficácia, uma série de situações.

Quando pensamos em competências devemos também lembrar que estas envolvem um compromisso social, ético e político dos professores no exercício de sua docência; e ainda, que tais competências são influenciadas por diferentes experiências, vivências e opções.

Veremos quais competências são exigidas do professor na atualidade, e em especial tratamos aqui do docente de LE, para que este atue com eficácia no processo de ensino-aprendizagem.

\section{Competências necessárias no ensino-aprendizagem}

Para Veiga (2006), ensinar é um trabalho laborioso que envolve elementos articulados: o professor, o aluno e o conhecimento. Segundo o autor, nem sempre há um consenso entre os professores a respeito do que se entende por ensino. Entretanto, é possível perceber que existem elementos coincidentes responsáveis pelas características fundamentais para a compreensão do ensino no contexto educacional. São eles:

- Intencionalidade: relaciona-se com o contexto educacional, a sociedade e a sua convivência com os outros.

- Interação e compartilhamento: diz respeito a um processo que se realiza entre pessoas. Ou seja, ensinar é trabalhar com, sobre e para seres humanos, implicando relações concretas entre pessoas.

- Afetividade: representa a presença da afetividade num processo de troca entre as pessoas na criação de um ambiente humanizado e propício ao processo de ensino-aprendizagem. 
- Construção de conhecimento e rigor metodológico: em última instância, a construção do conhecimento é do sujeito. Entretanto, ao professor cabe a tarefa de criar situações e formas que propiciem o vínculo do conhecimento com a realidade do aluno e com a sua prática social mais ampla.

- Planejamento didático: remete aos fins e objetivos a serem alcançados e que devem ser pensados previamente. É o compromisso do professor no que diz respeito ao ensino como possibilidade de alcançar as finalidades mais gerais da educação postas para um determinado nível de ensino.

Tais elementos demonstram que o ensino envolve ações variadas e distintas, exigindo do professor competências fundamentais que devem ser construídas em seu processo de formação profissional. Neste sentido, conforme já apontamos anteriormente, ser professor demanda muito mais do que dominar conteúdos e conhecimentos sobre uma determinada matéria escolar.

Percebemos que estes elementos estão diretamente ligados às competências do professor, pois elas englobam de forma mais detalhada todos estes itens acima mencionados.

Vejamos agora alguns autores que tratam das competências docentes exigidas na atualidade.

Paulo Freire (2001) faz uma reflexão sobre os saberes necessários à prática educativa-crítica, fundamentada na ética e alicerçada na pesquisa. Freire explica que sem autonomia não há prática de ensino e nem aprendizagem, que a competência técnicocientífica deve ser inerente ao professor e que o discurso engajado sozinho não resolve, se a ação pedagógica não for aberta às mudanças. Para o autor, a prática pedagógica docente deve estar inserida na dimensão social da formação humana; ele advertiu que é preciso uma postura vigilante contra todas as práticas de desumanização.

Freire discorre sobre os excluídos e mecaniza uma nova ética de trabalho docente com base no reconhecimento de que o ser humano está submetido a condicionamentos genéticos, culturais e sociais, mas que não é determinado por eles e pode quebrar as correntes estabelecidas pelo sistema imperante. Para Freire, ensinar é muito mais 
do que apenas transferir conteúdos, como muitos pensavam em décadas passadas, é criar possibilidades para a produção e construção do conhecimento. Para ele, docente e discente são sujeitos dos acontecimentos. Ele reforça a prática docente democrática, a qual considera o aprendiz como sujeito do processo de aprendizagem. Segundo Freire, o professor deve gostar do seu trabalho, querer bem aos seus alunos, ter afetividade para com todos, respeitar as pessoas como elas são e suas culturas, entre outras características.

Percebemos que a base do pensamento de Freire está, portanto, em se respeitar a cultura e o conhecimento individual de cada aluno:

Por isso mesmo, pensar certo coloca ao professor ou, mais amplamente, à escola, o dever de não só respeitar os saberes com que os educandos, sobretudo os das classes populares, chegam a ela - saberes socialmente construídos na prática comunitária - mas também, como há mais de trinta anos venho sugerindo, discutir com os alunos a razão de ser de alguns desses saberes em relação com o ensino dos conteúdos. (FREIRE, 2001, p. 30)

Trazer para sala de aula o conhecimento que nossos alunos já possuem, fazer a ponte entre esse conhecimento e o conteúdo ensinado em sala é, segundo o autor, fundamental para que o ensino faça algum sentido para eles; além do que, tratar de temas conhecidos por eles faz com que a interação social realmente ocorra.

Perrenoud (2000) aponta inicialmente para o conceito de competência: o professor deve ter habilidade de colocar o saber em prática e ter atitude positiva no que se refere à iniciativa e desenvolvimento do trabalho e à sua realização com eficiência e eficácia. Assim, a partir desta ideia, ele organizou dez grandes famílias de competências docentes: 1) organizar e dirigir situações de aprendizagem; 2) administrar a progressão das aprendizagens; 3) conceber e fazer evoluírem os dispositivos de diferenciação; 4) envolver os alunos em suas aprendizagens e em seu trabalho; 5) trabalhar em equipe; 6) participar da administração da escola; 7) informar e envolver os pais; 8) utilizar novas tecnologias; 9) enfrentar os deveres e os dilemas éticos da profissão; e, 10) administrar sua própria formação contínua. 
Todas estas competências apresentadas por Perrenoud muitas vezes são vistas como ideologias, que não se encaixam na realidade brasileira devido à falta de políticas que possibilitem a construção de tais competências. Membros da comunidade escolar (professores, coordenadores e diretores) concordam que são competências necessárias e importantes, mas reconhecem que muitas vezes não é possível ao professor alcançar algumas delas devido à falta de possibilidades, falta de estrutura nas escolas, falta de recursos. Por outro lado, existem algumas ilhas de excelência, seja no setor público ou privado, em que o professor pode contar com um apoio que permite chegar-se a um bom nível em todas estas competências, em que ele encontra recursos tecnológicos, cursos de formação continuada, além de acompanhamento adequado por parte do corpo gestor.

O próprio autor, ao elaborar sua obra, estava ciente da impossibilidade de se alcançar todas estas competências devido a diferentes fatores:

Ninguém pode observar e conceituar todas as facetas do ofício de professor, conceber com a mesma precisão e a mesma pertinência todas as competências correspondentes. Pensei em mobilizar, sobre cada tema, um especialista diferente. Recuei diante dos problemas de coordenação que tal empreendimento coletivo suscitaria, mas também diante de suas dificuldades teóricas: nenhum professor, nenhum pesquisador recorta a realidade complexa da função exatamente como os outros. As facetas do trabalho pedagógico, as famílias de competências não existem "objetivamente", elas são construídas, certamente a partir do real, mas também de tramas conceituais e de pré-conceitos teóricos e ideológicos. (PERRENOUD, 2000, p. 172)

Vemos que também o autor concorda com o fato de que as competências são construídas segundo a realidade em que se apresentam. Essa interferência do meio vai determinar o nível de cada competência, se razoável, boa ou ruim; a realidade vivenciada por cada docente atua de maneira determinante sobre sua prática, portanto, não apenas as competências possuem características diferentes como também o nível de desenvolvimento de cada uma varia muito. Assim, 
o autor procura, em sua obra, apresentar práticas que "deveriam" orientar as formações iniciais e contínuas, que contribuem para melhorar o processo de ensino-aprendizagem.

Morin (2003) aborda temas que enriquecem o debate sobre os saberes necessários aos docentes. Com sua visão multidisciplinar da educação escolar, este autor coloca suas principais ideias sobre a educação do amanhã nesta obra, Os sete saberes necessários à educação do futuro, que assim ficou dividida: "As cegueiras do conhecimento: o erro e a ilusão"; "Os princípios do conhecimento pertinente"; "Ensinar a condição humana"; "Ensinar a identidade terrena"; "Enfrentar as incertezas"; "Ensinar a compreensão"; e "A ética do gênero humano".

Nessa obra, Morin aborda problemas específicos de cada nível da educação, seja ela básica, secundária ou superior, mas muitos destes problemas são frequentemente ignorados nos programas escolares. Seu texto é mais centrado no desenvolvimento do cidadão. Para o autor, falta integração entre as disciplinas, de forma que elas caminhem sempre para a ética e, sobretudo, respeito ao planeta. Segundo o autor, se houvesse tal integração talvez também houvesse uma mudança de pensamento, uma transformação da visão fragmentada do mundo, a qual impede a visão da realidade e faz com que os problemas permaneçam invisíveis, sobretudo para os governantes. Ele não propõe uma destruição total dos atuais programas de ensino, apenas sugere uma real integração entre as diferentes áreas, de forma que haja um objetivo comum para todos, o que, segundo o autor, seria a salvação da espécie humana.

Na verdade, a dominação, a opressão, a barbárie humanas permanecem no planeta e agravam-se. Trata-se de um problema antropo-histórico fundamental, para o qual não há solução a priori, apenas melhoras possíveis, e que somente poderia tratar do processo multidimensional que tenderia a civilizar cada um de nós, nossa sociedade, a Terra.

Sós e em conjunto com a política de civilização, a reforma do pensamento, a antropo-ética, o verdadeiro humanismo, a consciência da Terra-Pátria reduziriam a ignomínia no mundo. (MORIN, 2003, p. 114) 
Notamos que o pensamento de Morin caminha em direção a um propósito ético e político para toda a humanidade, seu pensamento é muito mais amplo em relação aos demais autores aqui abordados, se pensarmos que visa não apenas o espaço da sala de aula, mas pretende a partir deste mudar um espaço maior, o planeta. Ainda que seus objetivos sejam amplamente mais pretensiosos, há com certeza, no pensamento de Morin, uma possibilidade grande de atuação do docente, que pode, com sua prática pedagógica, interferir diretamente na formação do cidadão, fomentando em seus alunos a consciência humana, solidária em relação não só ao próximo, como também à natureza.

Tardif (2002) aborda aspectos que envolvem a prática docente, ao falar da carência dos mestres, do problema econômico, das diferenças de tratamento em comparação a outras profissões; trata também da falta de consideração pelos profissionais da educação.

O autor explica o panorama da década de 1990, as reformas educacionais, a divisão de saberes, a necessidade de não separar o conhecimento universitário do conhecimento prático. Segundo Tardif, o saber docente está relacionado com a prática e formação profissional, com os saberes da ciência da educação, com a identidade de cada um. Desta maneira o autor questiona: quais saberes são mais importantes? Quais conhecimentos devem ser desenvolvidos? Quais competências e habilidades são melhores? E, como resposta a estas questões. ele apresenta quatro saberes docentes necessários: saberes da formação profissional; saberes da disciplina; saberes curriculares; e saberes experienciais. Sua obra é uma das que mais enfatiza a importância da pessoa do professor.

Ainda hoje, na maioria dos países, embora os professores ocupem a posição mais importante entre os agentes escolares, embora o papel deles seja tão importante quanto o da comunidade científica, no que se refere ao aspecto sociocultural, eles se encontram, com muita freqüência, em último lugar na longa seqüência dos mecanismos de decisão e das estruturas de poder que regem a vida escolar. Em suma, seu poder, não somente na vida dos estabelecimentos escolares, mas na organização e no desenvolvimento de seu próprio trabalho, é realmente muito reduzido. Entretanto, se 
quisermos que os professores sejam sujeitos do conhecimento, precisaremos dar-lhes tempo e espaço para que possam agir como atores autônomos de suas próprias práticas e como sujeitos competentes de sua própria profissão. (TARDIF, 2002, p. 243)

O autor defende uma ampla valorização do professor enquanto profissional, propondo uma maior autonomia para este, e ainda sugere também que haja uma parceria real entre todos os agentes que constituem o processo de formação docente, ou seja, o aluno de licenciatura, o pesquisador e o docente em atuação. Segundo Tardif, é necessário que todos atuem em conjunto para que formação e prática andem juntas, que as teorias criadas no âmbito das universidades realmente sirvam de suporte à prática docente.

Todas as competências mencionadas pelos autores aqui citados tratam ora da pessoa do professor, do aluno, do conhecimento de ambos, ora da relação entre aluno, professor e conhecimento. Verificase que, apesar de cada autor ter sua linha de pensamento, todos apontam para um mesmo ponto comum: a qualidade do processo de ensino-aprendizagem. Esses autores foram escolhidos devido à atualidade de suas teorias, e, por se tratar de estudos fundamentais quando falamos de competências docentes, ainda que diferentes, tais teorias se complementam, no sentido de sugerir ações em diversas áreas e campos fundamentais para uma boa prática pedagógica.

Neste primeiro momento da reflexão percebemos que alguns elementos são comuns a todas as teorias que tratam dos saberes docentes, que buscam o aperfeiçoamento da prática docente. São eles: criatividade, sensibilidade, habilidade, intuição, criticidade, socialização, ética, autonomia, iniciativa, conhecimento. Quando falamos em formação de professores, prática docente, processo de ensino-aprendizagem, em algum momento nos deparamos com um destes elementos, pois eles abarcam todos os campos envolvidos no ensino: o professor, o aluno e o currículo.

Vimos até este ponto da discussão alguns exemplos de competências gerais que são importantes para todos os docentes, não importando a sua área. Se o docente souber equilibrar tais competências, buscar ter um bom nível em algumas delas, com certeza sua prática pedagógica terá um desenvolvimento mais adequado, 
fazendo com que este profissional obtenha uma avaliação positiva diante de seus pares.

A partir de agora trataremos especificamente do professor de LE, que deve não apenas buscar estas competências que acabamos de mencionar, mas que também deverá apresentar outras competências específicas para seu campo de atuação.

\section{Competências necessárias ao professor de LE}

Todas as competências apontadas na seção anterior têm sua importância e podem variar de pessoa para pessoa. Vale lembrar que as concepções mencionadas acerca dessas competências são subjetivas, portanto, ainda que nos auxiliem neste caminho reflexivo, sabemos que elas permitem interpretações variadas e dependem de diversos fatores para existirem, são influenciadas pelo meio em que se desenvolvem, pela história de vida do docente, pela estrutura oferecida pela instituição em que este atua; enfim são muitos os aspectos responsáveis pela construção dessas competências. Entendemos também que as competências oferecem benefícios reais para a prática docente, isto é, aquele professor que busca refletir sobre suas próprias competências, procurando equilibrá-las de modo que desenvolva todas razoavelmente, terá uma projeção profissional melhor do que aqueles que não se importam em sanar suas dificuldades. Por isso, acreditamos que as competências devem ser estudadas e aperfeiçoadas, assim talvez possamos nos aproximar do nosso objetivo constante, enquanto educadores: uma prática docente melhor e consequentemente um ensino de qualidade. Importa-nos aqui, sobretudo, a melhora do processo de ensino-aprendizagem de LE.

Para o professor de LE são necessárias ainda outras competências específicas de sua área, inerentes a este profissional. Salientamos que também a definição quanto a estas competências é ampla e divergente entre vários autores. Quem bem apresentou tais divergências foram Rocha e Silva (2007, p. 3) ao tratarem das concepções de competência linguística e comunicativa; competência gramatical, sociolinguística e estratégica. Esses autores apresentam um modelo mais atual denominado de "competência de linguagem" 
proposto por Bachman (1990). Em sua pesquisa, Rocha e Silva adotam um referencial proposto por Almeida Filho (1999), que também é, em nossa opinião, o mais adequado para a atualidade, pois evidencia as competências consideradas desejáveis ao profissional atuante no processo de ensino-aprendizagem de LE. São elas: competência linguístico-comunicativa, competência aplicada, competência teórica, competência implícita e competência profissional.

Segundo Almeida Filho (1993, 2004, 2006), quando um professor se coloca no lugar e momento de ensinar, um feixe ou "aglomerado de conhecimentos informais anteriormente construído", o qual abarca desde percepções, intuições, memórias, sacadas, imagens e crenças até pressupostos teóricos explícitos, tudo sob uma configuração de atitudes, posta-se a serviço desse ensinar, embasando todas as suas tomadas de decisões. A "qualidade, natureza ou textura da ação de ensinar, portanto, vai depender de uma combinação ou nível de uma ou mais de cinco competências básicas": lingüístico-comunicativa, implícita, teórica, aplicada e profissional. Segundo Almeida Filho (1993, 2004, 2006), para ensinar, o professor necessita, no mínimo, das competências lingüístico-comunicativa e implícita. (ROCHA; SILVA, 2007, p. 75-76)

Apesar de concordarmos com Almeida Filho acerca da denominação destas competências, sua definição e delimitação, não somos a favor de sua última colocação; acreditamos que para ensinar bem o professor necessite, sim, de várias outras competências, além da linguístico-comunicativa e da implícita, que são aquelas apresentadas na primeira parte deste estudo, contempladas na área da educação. Todas se complementam e dão à ação do professor um caráter mais coletivo e menos individualista.

Quem explicitou as cinco competências apontadas por Almeida Filho foi Saraiva (2005), abordando detalhadamente cada uma delas. Também podemos encontrar outras abordagens acerca do tema em estudos propostos por Alvarenga (1999), Teixeira da Silva (2000) e Basso (2001), mas aqui apontaremos uma síntese apresentada por Concário (2007, p. 2) cuja abordagem clara e objetiva nos pareceu mais adequada para elucidar nossa reflexão. 
Competência lingüístico-comunicativa - Conhecimento da língua que ensina, da língua materna dos alunos, habilidades no uso da linguagem.

Competência implícita - Conhecimento pessoal oriundo da experiência direta, nem sempre explicitável (intuições, impressões).

Competência teórica - Conhecimento acadêmico/teórico sobre língua, linguagem, aprendizagem, ensino, normalmente reconhecido como proveniente de outras pessoas.

Competência aplicada - Conhecimento de prática: aplicações pelo professor daquilo que ele conhece da teoria dos outros, e de suas crenças e intuições implícitas.

Competência profissional - Habilidade para cumprir as atividades esperadas de um professor na relação com as instituições, com os colegas e com os alunos. (CONCÁRIO, 2007, p. 35)

Notamos que, ao se descreverem as competências, fala-se também em habilidades no uso da linguagem, e isto ocorre porque realmente a ligação entre estes termos é muito forte. Para ser um bom professor de LE é necessário ter certas habilidades, e neste caso as que mais se sobressaem em relação às demais são a proficiência na língua alvo e a prática de ensino.

O desenvolvimento destas habilidades já começa na formação do futuro professor, durante sua graduação. Este pensamento se confirma em outros estudos, os quais agora apresentamos.

Consolo, Martins e Anchieta (2009) apontam, em sua pesquisa, para o desenvolvimento de habilidades orais em LE, afirmando que uma porcentagem de alunos formados em cursos de Letras no Brasil não atinge níveis de proficiência oral adequados para lecionar satisfatoriamente nas línguas estrangeiras de suas certificações, e que este fato influencia negativamente a qualidade do ensino de LE no país. Apoiados também na linha teórica de Almeida Filho (1999), relatam a importante influência das competências na prática docente:

Nesse sentido, sabe-se que a abordagem de ensinar e as competências do docente influenciam na prática pedagógica, 
bem como na escolha do material, no desenvolvimento das aulas, na forma de avaliar os alunos e nas habilidades privilegiadas. Uma vez que essa consciência sobre o processo de ensino-aprendizagem designa a competência implícita do professor e que, a partir dela, faz-se evidente sua competência aplicada, pode-se afirmar que os procedimentos adotados por esse professor, consciente ou inconscientemente, em sala de aula, determinam o êxito ou insucesso na aprendizagem dos alunos. (CONSOLO; MARTINS; ANCHIETA, 2009, p. 32)

Os autores acreditam que para se obter um diagnóstico acerca do ensino e da qualidade da produção oral dos futuros professores de LE é importante considerar aspectos fundamentais do processo de ensino-aprendizagem que se referem não apenas à abordagem de ensinar do professor mas também à abordagem de aprender dos alunos. Trata-se de um processo de interação entre os sujeitos envolvidos e, portanto, todos os sujeitos do processo de ensino-aprendizagem devem ser considerados na análise.

Os autores supracitados apresentam como principais aspectos observados em sua pesquisa: a atuação do professor na interação em sala de aula; a atuação dos alunos na interação; e os recursos e materiais didáticos para o desenvolvimento das habilidades orais.

Segundo os autores, o fracasso ou sucesso na aquisição de uma LE se dá não somente pelas ideias que o aluno tem sobre a língua-alvo, mas também pela relação que o professor estabelece com os aprendizes, com o material didático e, principalmente, com a língua alvo.

Sabemos que todos estes aspectos são desenvolvidos nos docentes durante toda sua vida profissional e estes, muitas vezes, já trazem consigo exemplos herdados de seus professores. E que toda prática docente precisa ser revista e atualizada. Muitos profissionais são prejudicados por se apegarem a práticas engessadas, tradicionais, recusando-se a mudar sua maneira de ensinar.

Os cursos de Letras geralmente certificam o professor para atuar em língua materna e uma LE, e a grande maioria dos currículos apresenta uma carga horária bem maior de disciplinas ligadas à língua materna em detrimento da estrangeira. Com isso, certamente o aluno de Letras terá poucas chances de desenvolver adequadamente sua 
proficiência na LE, e, ao se formar e ingressar nas instituições de ensino, continuará sem poder aperfeiçoar todas as suas habilidades linguísticas, pois geralmente os cursos de línguas sejam em instituições públicas ou privadas, têm um foco específico, somente leitura, ou escrita, e assim por diante, o que muitas vezes impede o aperfeiçoamento linguístico do docente.

E a prática pedagógica? Segunda habilidade que consideramos de grande importância, ao lado da proficiência linguística, para que o docente tenha um equilíbrio entre todas as competências necessárias para sua boa atuação no ensino de LE, também tem seu desenvolvimento já nos cursos de graduação, nas disciplinas de prática de ensino e nos estágios supervisionados. O grande desafio neste momento tem sido a ponte entre a teoria e prática, e muitos recémformados se sentem inseguros, pois geralmente concluem os cursos de graduação cheios de teorias e com pouca prática, não sabem o que fazer com toda esta teoria.

Neste sentido, o texto de Simões (2011) mostra a importância do estágio e da relação entre teoria e prática, pois somente colocar os alunos-professores para realizar o estágio sem uma prática reflexiva muito pouco ajuda na construção do futuro professor.

Neste trabalho de pesquisa, nossa intenção era verificar se a partir da prática poderíamos trabalhar com a conscientização e autonomia dos alunos-professores para que eles pudessem questionar e modificar suas crenças, além de que pudessem fazer de maneira autônoma a ligação entre a teoria e a prática, para serem capazes de buscar soluções para os problemas cotidianos da profissão. (SIMÕES, 2011, p. 1516)

A autora atribui um importante valor à questão da autonomia dos futuros professores, e esta é uma das competências defendidas também por Freire (2001). Construir profissionais autônomos dentro de seu campo de atuação é fundamental para o êxito da instituição; porém, é necessário ter domínio sobre esta autonomia, verificar se a instituição realmente preza por este tipo de profissional, visto que muitas pessoas confundem autonomia com liberdade para agir da forma como bem entenderem. 
Simões também busca em seu estudo verificar se a partir da prática seria possível trabalhar com a conscientização acerca da autonomia dos alunos-professores, para que estes possam questionar e modificar suas crenças e ainda fazer, de maneira autônoma, a relação entre a teoria e a prática, sendo assim capazes de solucionar os problemas cotidianos da profissão. Neste sentido, Perrenoud (2002, p. 22) também afirma que, quando não há articulação entre a teoria e a prática, a construção de competências fica comprometida, impedindo assim o professor de desenvolvê-las adequadamente.

Seria necessário que o aluno-professor participasse ativamente da comunidade escolar durante seu período de estágio, e com isto ele teria oportunidades reais de desenvolver sua autonomia. Além do que, tendo responsabilidades no processo de construção da prática pedagógica, haveria uma oportunidade concreta de se estabelecer a ligação entre a teoria e a prática.

Neste sentido, o posicionamento de Simões complementa a proposta de Tardif (2002), o qual incentiva também uma parceria entre os profissionais que estão formando profissionais da educação (pesquisadores/professores universitários), os futuros professores (alunos dos cursos de licenciatura) e os professores em atuação nas escolas de ensino fundamental e médio.

Percebemos que são muitos os problemas que influenciam no desenvolvimento das competências necessárias para atuar como docente, e, no caso dos professores de LE, há ainda as habilidades relativas à língua ensinada, que, conforme apontamos acima, podem interferir ativamente na construção destas competências. Neste último caso, é importante que o professor tenha consciência de suas dificuldades e que busque, por meio de um aperfeiçoamento linguístico, saná-las durante sua formação pré-serviço e também em caráter de formação continuada.

Quando falamos de competências inerentes ao profissional do magistério, não há como não falar em habilidades, conhecimentos, capacidades, pois estes são termos diretamente ligados à construção dos saberes docentes, Por isso, nesta segunda parte do nosso texto, procuramos apresentar dois problemas que interferem na qualidade da prática docente e consequentemente do desenvolvimento de algumas competências, sobretudo a competência linguístico-comunicativa e a competência implícita. 
Sabemos que neste percurso feito pelo professor para poder se habilitar no exercício do magistério ocorrerão muitos problemas na construção dos saberes docentes necessários à sua atuação enquanto profissional, porém este deve estar sempre atento para buscar identificar aquelas competências em que ele ainda possui dificuldades. Os pesquisadores, diretores e coordenadores pedagógicos podem e devem ajudar os docentes nesta busca pelas competências ideais. No entanto, cabe somente ao professor saber, dentre todas as competências existentes, quais ele necessita aperfeiçoar, considerando o ambiente em que atua, o nível de ensino para o qual leciona, as possibilidades espaciais e materiais encontradas.

Quais competências são necessárias para que um professor seja considerado um bom profissional na atualidade? Após todas estas reflexões, podemos elencar algumas: boa formação, domínio das tecnologias, atualização didática, trabalho em equipe, planejamento e autoavaliação contínuos, atitude e postura profissionais, domínio da disciplina que ensina - aqui no caso do professor de LE, incluem-se todos os conhecimentos inerentes à língua ensinada, muito bem delimitados por Almeida Filho (2004) ao considerar que, para a ação de ensinar, o professor necessite minimamente de duas competências: a linguístico-comunicativa e a implícita, sendo que a primeira lhe permitirá ensinar o que sabe sobre a língua em questão e envolver os aprendentes numa teia de linguagem na língua-alvo, enquanto a segunda, a implícita, lhe facultará agir espontaneamente para ensinar através de procedimentos tidos como apropriados. Concordamos com Almeida Filho acerca da definição destas duas competências, o que não significa, todavia, que sejam suficientes para o bom professor. Assim sendo, o leque das competências necessárias inclui as várias outras competências aqui elencadas.

Estas competências nada mais são do que a síntese de todas as que apresentamos nesta discussão, umas mais detalhadas do que outras, sob visões diferentes, porém visando a um objetivo comum: um docente mais capacitado e um ensino de LE de melhor qualidade.

Salientamos ainda que, neste estudo, tratamos das competências sob uma perspectiva educacional e com relação à atuação de professores de LE. Neste sentido, procuramos trazer alguns 
teóricos que julgamos mais importantes, os quais acreditamos serem suficientes para tal discussão.

\section{Considerações Finais}

Acompanhando o pensamento de Macedo (2008), é qualificado aquele que supera todas as restrições e impedimentos encontrados em seu local de trabalho e consegue, com o que tem, fazer o seu melhor. Ainda que com uma formação deficiente durante a graduação, o professor pode procurar aperfeiçoar-se para desenvolver as competências que ficaram prejudicadas; buscar, por meio de pesquisas, atualizar-se; refletir constantemente sobre sua prática para melhorá-la; conversar com seus colegas de profissão para trocar experiências; não esperar que sua formação seja complementada apenas pela instituição em que trabalha (ainda que isto seja desejável).

Não esperamos que o bom professor de LE possua todas as competências aqui citadas, mas sim que busque um equilíbrio entre elas, afinal, o que adianta, por exemplo, ser totalmente proficiente, ter total domínio da língua ensinada se não tiver uma boa prática pedagógica, e vice-versa. Não podemos dizer que uma competência seja melhor ou mais importante do que outra, porém se uma delas estiver visivelmente fraca, afetará todas as outras, prejudicando a prática docente.

Encontramos esta sugestão também nos PCN (1997), que apontam a necessidade de não se ter uma abordagem fundamentada apenas em teorias sobre a competência comunicativa, mas também buscar uma abordagem sociocultural que privilegie a interação com pares mais desenvolvidos, pois isto possibilitará um desenvolvimento cognitivo/sócio-histórico de todos os indivíduos envolvidos do processo de ensino-aprendizagem.

Saraiva (2005, p. 20), em seu minucioso estudo sobre as competências docentes, destaca o caráter inacabado das pesquisas sobre as competências do professor. Segundo o autor, a configuração da competência profissional do professor é indefinida, imprecisa, mutante e variável, no tempo, no espaço e entre indivíduos. Definir e configurar a competência profissional do professor de LE, portanto, é tarefa sempre inacabada, imprecisa e imperfeita: um alvo móvel, que 
dificilmente será abatido em termos definitivos. Concordamos com sua afirmação, visto que a cada época se faz necessário um mapeamento destas competências, assim como uma delimitação daquelas que são realmente necessárias ao profissional desejado.

$\mathrm{Na}$ atualidade percebemos que o professor de LE, ainda que proficiente na língua-alvo, não terá um perfil que possa atender às exigências do mercado e seus objetivos pessoais e profissionais caso também não tenha o domínio das novas tecnologias e, sobretudo, não saiba trabalhar em equipe, pois o individualismo não é mais aceito nas instituições de ensino que buscam trabalhar seguindo uma gestão democrática, participativa e colaborativa.

Acreditamos ainda que, atualmente, é imprescindível para um bom profissional buscar interagir com seus alunos, criando um ambiente agradável para o ensino, atualizar-se pesquisando sobre novas teorias e abordagens de ensino, ou seja, estar sempre de acordo com sua época, acompanhando as mudanças, sensível aos novos caminhos que a educação está trilhando.

Como um texto que depois de escrito necessita de revisão, às vezes até várias leituras, também o professor, depois de formado, durante toda sua atuação profissional, precisa de vez em quando "se revisar", pedir opiniões de outros colegas ou até mesmo de especialistas, e, assim, adquirir ou desenvolver as competências necessárias para ser um bom profissional. As competências nunca vêm prontas com o profissional. Elas são construídas ao longo de toda a sua atuação no magistério, com a prática do dia a dia, nos cursos de capacitação, na troca de experiências e, principalmente, elas se constroem conforme o desejo de cada um em querer ou não conquistálas, segundo o engajamento de cada profissional em relação à qualidade de ensino que pretende oferecer.

\section{Referências}

ALMEIDA FILHO, José Carlos P. Dimensões comunicativas no ensino de línguas. Campinas: Pontes, 1993. 
- (Org.) O professor de língua estrangeira em formação. Campinas: Pontes, 1999.

- O professor de língua(s): profissional, reflexivo e comunicacional. Horizontes de Lingüística Aplicada, v. 3, n. 1, p. 718, 2004.

ALVARENGA, Magali B. Configuração de competências de um professor de língua estrangeira (inglês): implicações para a formação em serviço. Tese (Doutorado em Linguística Aplicada) - Instituto de Estudos da Linguagem, UNICAMP, Campinas, 1999.

BACHMAN, Lyle F. Fundamental considerations in language testing. Oxford: Oxford University Press, 1990.

BASSO, Edcleia A. A construção social das competências necessárias ao professor de língua estrangeira: entre o real e o ideal um curso de Letras em estudo. Tese (Doutorado em Linguística Aplicada) Instituto de Estudos da Linguagem, UNICAMP, Campinas, 2001.

BRASIL. Ministério da Educação e Cultura. Parâmetros curriculares nacionais: introdução. Brasília, 1997.

CAMARGO, Maria Lúcia N. Formação de professores: uma reflexão sobre as competências implícita e explícita. In: CONSOLO, Douglas A.; SILVA, Vera Lúcia T. (Org.). Olhares sobre competências do professor de língua estrangeira: da formação ao desempenho profissional. 1. ed. São José do Rio Preto: HN, 2007. p. 19-33.

CONCÁRIO, Marcelo. A consciência lingüística e o desenvolvimento de competências do professor de língua estrangeira. In: CONSOLO, Douglas A.; SILVA, Vera Lúcia T. (Org.). Olhares sobre competências do professor de língua estrangeira: da formação ao desempenho profissional. 1.ed. São José do Rio Preto: HN, 2007. p. $35-59$. 
CONSOLO, Douglas A.; MARTINS, Maisa J.; ANCHIETA, Priscila P. Desenvolvimento de habilidades orais em língua inglesa no curso de letras: uma experiência. Em Aberto, v. 22, p. 31-45, 2009.

FREIRE, Paulo. Pedagogia da autonomia: saberes necessários à prática educativa. 18. ed. Rio de Janeiro: Paz e Terra, 2001.

MACEDO, Lino. Competências na educação. 2008. Disponível em: http://www.rededosaber.sp.gov.br/contents/SIGS-

CURSO/sigsc/upload/br/site_25/File/competencias_na_educacao_cr.pdf. Acesso em: 17 out 2011.

MORIN, Edgar. Os sete saberes necessários à educação do futuro. Tradução de Catarina Eleonora F. da Silva e Jeanne Sawaya. São Paulo: Cortez: UNESCO, 2003.

PERRENOUD, Philippe. A formação dos professores no século XXI. In: - As competências para ensinar no século XXI: a formação dos professores e o desafio da avaliação. Porto Alegre: Artmed, 2002. p. 11-33.

2000.

10 novas competências para ensinar. Porto Alegre: Artmed,

ROCHA, Cláudia H.; SILVA, Kleber A. O professor de língua estrangeira em formação: os gêneros discursivos como meio para o desenvolvimento de competências. In: CONSOLO, Douglas A.; SILVA, Vera Lúcia T. (Org.). Olhares sobre competências do professor de língua estrangeira: da formação ao desempenho profissional. 1. ed. São José do Rio Preto: HN, 2007. p. 61-79.

SARAIVA, Pedro S. Requisitos e expectativas na construção da competência profissional de ensinar LE. Dissertação (Mestrado em Linguística Aplicada) - Instituto de Letras, UnB, Brasília, 2005.

SIMÕES, Gisele M. O impacto do estágio nas crenças pedagógicas de professores de inglês em formação. Tese (Doutorado em Estudos 
Douglas A. Consolo \& Cristina F. C. Porto

Linguísticos) - Instituto de Biociências, Letras e Ciências Exatas, UNESP, São José do Rio Preto, 2011.

TARDIF, Maurice. Saberes docentes e formação profissional. Petrópolis: Vozes, 2002.

TEIXEIRA DA SILVA, Vera Lúcia. Fluência oral: imaginário, construto e realidade num curso de Letras/LE. Tese (Doutorado em Linguística Aplicada) - Instituto de Estudos da Linguagem, UNICAMP, Campinas, 2000.

VEIGA, Ilma P. A. Ensinar: uma atividade complexa e laboriosa. In: Lições de didática. Campinas: Papirus, 2006. p. 13-33.

Recebido em: $27 / 10 / 2011$

Aceito em: $\quad 22 / 02 / 2012$

Title: Teachers' competences in the foreign language teachinglearning process 
Competências do professor no processo de ensino 